\title{
Development of an ISSR based SCAR marker to identify small cardamom Malabar (prostrate panicle) variety (Elettaria cardamomum Maton.)
}

Sherin Jose ( $\square$ sherinjose.b@gmail.com )

Indian Cardamom Research Institute https://orcid.org/0000-0002-2559-7398

Mary K Mathew

Indian Cardamom Research Institute

Anisha CS

Indian Cardamom Research Institute

Swapna Sasidharan

Indian Cardamom Research Institute

Rao YS

Indian Cardamom Research Institute

Research Article

Keywords: Elettaria cardamomum, ISSR, SCAR, variety-specific marker, prostrate panicle

Posted Date: February 18th, 2021

DOI: https://doi.org/10.21203/rs.3.rs-168166/v1

License: (c) (i) This work is licensed under a Creative Commons Attribution 4.0 International License.

Read Full License

Version of Record: A version of this preprint was published at Scientia Horticulturae on December 1st, 2021. See the published version at https://doi.org/10.1016/j.scienta.2021.110777. 


\section{Abstract}

Small cardamom (Elettaria cardamomum Maton) a perennial monocot, exhibits an array of variation in nature, mainly due to cross pollination. Based on the nature of the panicle orientation, cardamom is broadly grouped into three main 'cultivated types' - Malabar, Mysore and Vazhuka having prostrate, erect and semi-erect panicles respectively. These morphologically discriminative markers manifest itself during panicle emergence as is only possible. Among the three varieties Malabar variety is relatively superior with respect to different qualitative and quantitative characteristics. The objective of the present study was to develop and characterize molecular markers for enabling differentiation of Malabar variety at juvenile stage. One accession specific ISSR marker generated by UBC 866 was selected which consistently amplified an intact, distinct, $₫ 1500 \mathrm{bp}$ band specifically in individuals of Malabar variety, which was therefore cloned, sequenced and characterized. Ten primers were designed from the sequences for converting them to SCAR markers. The developed SCAR markers were tested for variety specificity and one primer pair (SBBT4F/SBBT3R) was validated using small cardamom accessions belonging to Malabar variety from different geographic locations and varieties with erect panicles as well as hybrids. The findings suggest that the SCAR marker is promising in identifying cardamom varieties having prostrate panicle (Malabar) and therefore is expected to make significant contributions in selection of F1 hybrids during breeding programmes.

\section{Introduction}

Small cardamom (Elettaria cardamomum Maton) popularly known as 'Queen' among spices, is a rhizomatous perennial belonging to the family Zingiberaceae. It is considered as one of the most favoured spices in national and international cuisines by virtue of its versatility to impart the unique flavour - the sweetness together with pungency and aroma, to sweets and savouries. Because of its richness in essential oil and therapeutic components, small cardamom becomes the raw material for various pharmaceutical formulations. India has a rich wealth of genetic resources of cardamom as the crop originated in the tropical forests of Western Ghats (Mayne 1951; Abraham and Tulasidas 1958) and thus has a long tradition since centuries in the country. The cardamom varieties are highly location specific and therefore different varieties are adapted to different geographical regions along the Western Ghats (Anon 2009). Hence development of high yielding varieties specific to particular eco-geographic situation is of paramount importance.

The three main cultivated types or natural varieties of cardamom viz. Malabar, Mysore and Vazhukka were grouped mainly based on the nature of the panicle - prostrate, erect and semi erect respectively and is regarded as the major discriminative morphological markers of cardamom (Madhusoodanan et al. 2002). Among the three varieties of small cardamom, Malabar variety possesses several distinctive characters such as its relative tolerance to drought (Sudarsan et al. 1991), higher number of panicles per plant (Padmini et al. 1999), early maturing character (Madhusoodanan et al. 2002) which is suitable for high density planting (Madhusoodhanan et al. 2002) and the relatively higher flavonoid content of $0.159 \%$ (Govindarajan et al., 1982). It was also reported that most of the resistant genotypes reported in 
cardamom are of Malabar type (Madhusoodhanan et al. 2002). However, all the three varieties and races of cardamom are inter-fertile and the observed variations are probably due to natural crossing (Korikanthimath 2003).

Cultivar selection during breeding programmes can be extremely difficult for a perennial like small cardamom as morphological discrimination of the three varieties is possible only after panicle emergence. Molecular markers including SCAR markers are an effective tool that can be used for varietal authentication and species identification at a very early developmental stage itself when key morphological features are indistinguishable (Das et al. 2008, Ghosh et al. 2011). SCAR markers have emerged as tools to distinguish between species that have similar morphology and phenotype, in several plants such as in spruce (Nkongolo et al. 2003), bamboo (Das et al. 2005), fenugreek (Surendra et al. 2012), gladiolus (Singh et al. 2017) and maple (Boyd et al. 2019).

Variety specific ISSR markers were previously identified in cardamom by the present authors (Sherin et al. 2013) but were not developed and validated as SCAR marker. In the present study we describe the conversion of ISSR derived specific marker to SCAR and its validation on small cardamom varieties. This is the first report on generation of SCAR markers in small cardamom.

\section{Materials And Methods}

\section{Plant material}

A total of 50 small cardamom accessions from the germplasm repository of Indian Cardamom Research Institute (ICRI), Spices Board, Kerala, India and two wild varieties from Regional Research Stations of ICRI were used to screen for variety specific markers (Table-1). Sources of genetic materials included 39 accessions and 11 released varieties. The accessions were selected based on the morphological analysis (IPGRI, 1994) and the panicle morphology was confirmed with the previous records available at ICRI. All the information concerning the collected samples was shown in Table 1. Secondly, the variety-specific marker was validated on 24 small cardamom accessions, which included 21 Malabar, 2 Mysore and 1 Vazhukka accessions. 
Table 1

Details of small cardamom accessions included in the present study

\begin{tabular}{|c|c|c|c|}
\hline SI.No & Accession name & Panicle morphology & Location \\
\hline 1 & ICRI 1 & Prostrate & Chakupallam, Kerala \\
\hline 2 & ICRI 2 & Erect & Pampadumpara, Kerala \\
\hline 3 & ICRI 3 & Prostrate & Sakleshpur, Karnataka \\
\hline 4 & ICRI 5 & Semi-erect & ICRI, Kerala \\
\hline 5 & MCC4 & Semi-erect & Mudigeri, Karnataka \\
\hline 6 & MCC6 & Erect & Chemmannar, Kerala \\
\hline 7 & MCC7 & Semi-erect & Chemmannar, Kerala \\
\hline 8 & MCC8 & Semi-erect & Vandiperiyar, Kerala \\
\hline 9 & MCC12 & Semi-erect short & Vandiperiyar, Kerala \\
\hline 10 & MCC34 & Prostrate & Thondimala, Kerala \\
\hline 11 & MCC35 & Prostrate & Pampadumpara, Kerala \\
\hline 12 & МсC36 & Semi-erect & Mavady, Kerala \\
\hline 13 & MCC37 & Prostrate & Mavady, Kerala \\
\hline 14 & MCC38 & Semi-erect & Mavady, Kerala \\
\hline 15 & МсС39 & Semi-erect & Pampadumpara, Kerala \\
\hline 16 & MCC40 & Prostrate & Mavady, Kerala \\
\hline 17 & MCC41 & Prostrate & Bodimettu, TN \\
\hline 18 & MCC42 & Semi-erect & Bodimettu, TN \\
\hline 19 & MCC43 & Semi-erect & Bodimettu, TN \\
\hline 20 & MCC44 & Prostrate & Santhanpara, Kerala \\
\hline 21 & MCC45 & Prostrate & Santhanpara, Kerala \\
\hline 22 & MCC46 & Semi-erect & Vandiperiyar, Kerala \\
\hline 23 & MCC47 & Semi-erect & Kailasanadu, Kerala \\
\hline 24 & MCC48 & Semi-erect & Kattappana, Kerala \\
\hline 25 & MCC50 & Prostrate & Chakkupalam, Kerala \\
\hline 26 & MCC51 & Semi-erect & Chakkupalam, Kerala \\
\hline 27 & MCC52 & Semi-erect & Thandigudi, TN \\
\hline
\end{tabular}




\begin{tabular}{|c|c|c|c|}
\hline SI.No & Accession name & Panicle morphology & Location \\
\hline 28 & MCC53 & Prostrate & Thandigudi, TN \\
\hline 29 & MCC55 & Semi-erect & Thandigudi, TN \\
\hline 30 & MCC58 & Prostrate & Mudigeri, Karnataka \\
\hline 31 & MCC60 & Prostrate & Mudigeri, Karnataka \\
\hline 32 & MCC64 & Semi-erect & Pampadumpara, Kerala \\
\hline 33 & MCC65 & Erect & Pampadumpara, Kerala \\
\hline 34 & MCC66 & Semi-erect & Pampadumpara, Kerala \\
\hline 35 & MCC67 & Erect & Meghamalai, TN \\
\hline 36 & MCC69 & Prostrate & Meghamalai, TN \\
\hline 37 & MCC70 & Semi-erect & Chenkara, Kerala \\
\hline 38 & MCC71 & Semi-erect & Santhanpara, Kerala \\
\hline 39 & MCC72 & Semi-erect & Anavilasam, Kerala \\
\hline 40 & MCC260 & Semi-erect & Puliyanmala, Kerala \\
\hline 41 & CRS Mudigere 1 & Prostrate & IISR, CRS Appangala, Kerala \\
\hline 42 & IISR Vijetha & Prostrate & Appangala, kodagu, Karnataka \\
\hline 43 & IISR Avinash & Prostrate & Kandanakolli, Kodagu \\
\hline 44 & MCC5 & Prostrate & Maniyargudi \\
\hline 45 & ICRI7 & Prostrate & Wayanad, Kerala \\
\hline 46 & ICRI4 & Prostrate & Lower Pulney hills, TN \\
\hline 47 & ICRI6 & Prostrate & Attappadi, Kerala \\
\hline 48 & Typical Mysore & Erect & Karnataka \\
\hline 49 & ICRI8 & Prostrate & Sakleshpur, Karnataka \\
\hline 50 & MCC334 & Erect & Anakkara, Kerala \\
\hline 51 & Amomum muricatum & Terminal & Kandanakolli, Kodagu \\
\hline 52 & Amomum subulatum & Terminal & Sikkim \\
\hline
\end{tabular}

\section{DNA Extraction And Quantification}


Fresh, young leaves of the small cardamom varieties were collected for DNA extraction. The method of genomic DNA isolation followed the procedure developed by the authors in a previous study (Mathew et al. 2013). The integrity and quality of DNA were evaluated using $1.0 \%$ agarose gels electrophoresis, and the concentration of genomic DNA was determined using a UV spectrophotometer (Hitachi) by measuring absorbance at A260 and A280 nm and also using Nanodrop UV/Vis spectrophotometer. Based on the quantification data, DNA dilutions were made in TE buffer to a final concentration of $25 \mathrm{ng} / \mu \mathrm{l}$ and stored at $-20^{\circ} \mathrm{C}$ for further use.

\section{Amplification Of ISSR Markers}

PCR amplifications were performed using UBC 866 in $25 \mu$ l reaction mixtures containing $25 \mathrm{ng}$ genomic

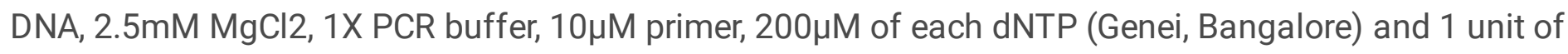
Taq DNA polymerase (Genei, Bangalore). Amplifications were carried out using a thermal cycler (Biorad) with an initial denaturation/activation step of $4 \mathrm{~min}$ at $95^{\circ} \mathrm{C}$ followed by 40 cycles of $30 \mathrm{~s}$ at $94^{\circ} \mathrm{C}, 60 \mathrm{sec}$ at annealing temperature and $2 \mathrm{~min}$ extension at $72^{\circ} \mathrm{C}$. A final extension for $10 \mathrm{~min}$ at $72^{\circ} \mathrm{C}$ was included. Optimal conditions were determined based on the resolvable PCR products generated by each primer. A negative control which contained all the PCR components except DNA (replaced by water) was included in every experiment to test for DNA contamination of the reagents. PCR products were subjected to electrophoresis on $2 \%$ agarose gels, stained with ethidium bromide $(0.5 \mu \mathrm{g} / \mathrm{ml})$ and documented in a gel documentation imaging (Biorad, USA). The fragment sizes were estimated by comparing to $250 \mathrm{bp}$ and 100bp DNA ladders (Genei, Bangalore).

\section{ISSR Analysis And Marker Selection}

Each of ISSR amplification was performed at least twice to verify the reproducibility of the results and only repeatable amplicons were selected. The amplified products were recorded as ' 1 ' for presence or ' 0 ' for absence of the bands. The presence of an ISSR band in a particular variety, and its absence in all the other varieties, was considered to be a variety-specific marker.

\section{Identification and gel elution of variety specific - ISSR markers}

Among the generated ISSR fingerprints, the $\sim 1500$ bp fragment that amplified specifically in Malabar variety (prostrate panicle) was eluted using GeneJET Gel Extraction kit (Thermoscientific) following manufacturer's instructions.

\section{Cloning And Sequencing Of ISSR UBC 866 Fragment}

The purified DNA fragment was ligated into pTZ57R (Fig-2) using InsTAclone PCR cloning kit (Thermoscientific) according to the manufacturer's instructions and transformed into ultra-competent Escherichia coli strain JM109 and then plated onto LB/ampicillin/IPTG/X-Gal plates. Positive colonies were determined by blue/white screening. The presence of the insert and its orientation in the purified plasmids was confirmed by colony PCR using M13 Universal primers. The reactions were performed in an appropriate thermocycler (Biorad, USA) adopting the following programme, $94^{\circ} \mathrm{C}$ for 2 minutes for initial 
denaturation, followed by 30 cycles of $94^{\circ} \mathrm{C}$ for $30 \mathrm{~s}, 45^{\circ} \mathrm{C}$ for $30 \mathrm{~s}$ and $72^{\circ} \mathrm{C}$ for $1 \mathrm{~min}$. This was followed by $72^{\circ} \mathrm{C}$ for five minutes for final extension. PCR products were separated and the colonies with desired size of insert were sequenced, using M13 universal primers in both forward and reverse directions, by Scigenome (Kochi, Kerala) using an automated ABI 3100 DNA sequencer (Applied Biosystems, Foster City, CA) method.

\section{Sequence Data Analysis, Scar Primer Design And Validation}

With the obtained nucleotide sequence, the similarity of the sequence was determined using the BLAST program (https://blast.ncbi.nlm.nih.gov/Blast.cgi). Based on the sequences of the cloned ISSR product, ten pairs of SCAR primer was designed using the Primer3 software. Care was taken to avoid possible secondary structure or primer dimer generation, false priming to match melting temperatures and to achieve appropriate internal stability while generating SCAR primers. The SCAR primers were synthesized through Sigma Aldrich Inc. Bangalore, India. To conduct primer validation, twenty-four selected small cardamom accessions were amplified with the SCAR marker. SCAR-PCR was performed in a final volume of $20 \mu \mathrm{l}$ consisted of $25 \mathrm{ng}$ of DNA from each sample, $1 \mathrm{x}$ reaction buffer, $2.5 \mathrm{mM}$ of $\mathrm{MgCl} 2,200 \mu \mathrm{M}$ each of dNTPs, $10 \mu \mathrm{M}$ of each SCAR primer and 1 unit of Taq DNA polymerase. Annealing temperatures was optimized for SCAR primers. The reactions were performed in Eppendorf Master Cycler with the program$94^{\circ} \mathrm{C}$ for $4 \mathrm{~min}$, followed by 35 cycles at $94^{\circ} \mathrm{C}$ for $45 \mathrm{~s}, 53-57^{\circ} \mathrm{C}$ for $1 \mathrm{~min}$ and $72^{\circ} \mathrm{C}$ for $2 \mathrm{~min}$ and a final extension at $72^{\circ} \mathrm{C}$ for $10 \mathrm{~min}$.

\section{Results}

\section{ISSR analysis and variety specific ISSR marker identification}

Small cardamom accessions from three botanical varieties (Table 1, Figure-1) were analyzed using ISSR primers. A total of 18 primers that generated clear, reproducible polymorphic bands (Table 2) were selected from the initial 35 primers analysed for the study. The amplified fragments were within a range of 180 to 2000 bp. Six ISSR primers had given a high percentage (100 \%) of polymorphic bands. The average number of loci per primer was 11.17 and the number of polymorphic loci generated per primer was 10.05 . Among the analysed genotypes, 191 (93.63\%) of the ISSR fragments were found to be polymorphic. 
Table 2

Details of ISSR primers analyzed, number of polymorphic loci and percentage of polymorphism obtained from fifty cardamom accessions and two out group varieties.

\begin{tabular}{|c|c|c|c|c|c|c|c|}
\hline $\begin{array}{l}\text { SI } \\
\text { No }\end{array}$ & $\begin{array}{l}\text { Primer } \\
\text { (UBC) }\end{array}$ & $\begin{array}{l}\text { Primer } \\
\text { Sequence }\end{array}$ & $\begin{array}{l}\text { Annealing } \\
\text { Temperature } \\
\left({ }^{\circ} \mathrm{C}\right)\end{array}$ & $\begin{array}{l}\text { Fragment } \\
\text { size } \\
\text { range } \\
\text { (bp) }\end{array}$ & $\begin{array}{l}\text { Number } \\
\text { of } \\
\text { fragments }\end{array}$ & $\begin{array}{l}\text { Number of } \\
\text { polymorphic } \\
\text { loci }\end{array}$ & $\begin{array}{l}\text { Polymorphism } \\
\text { (\%) }\end{array}$ \\
\hline 1 & 807 & $(\mathrm{AG})_{8} \mathrm{~T}$ & 49 & $\begin{array}{l}350- \\
1250\end{array}$ & 17 & 16 & 94.12 \\
\hline 2 & 808 & $(A G)_{8} \mathrm{C}$ & 52 & $\begin{array}{l}270- \\
1560\end{array}$ & 13 & 12 & 92.31 \\
\hline 3 & 810 & $(\mathrm{GA}){ }_{8} \mathrm{~T}$ & 46 & $\begin{array}{l}300- \\
1750\end{array}$ & 10 & 9 & 90 \\
\hline 4 & 812 & $(\mathrm{GA})_{8} \mathrm{~A}$ & 52 & $\begin{array}{l}200- \\
1000\end{array}$ & 10 & 10 & 100 \\
\hline 5 & 828 & $(\mathrm{TG}){ }_{8} \mathrm{~A}$ & 53 & $\begin{array}{l}220- \\
1450\end{array}$ & 15 & 15 & 100 \\
\hline 6 & 835 & $(A G){ }_{8} Y C$ & 57 & $\begin{array}{l}180- \\
2000\end{array}$ & 21 & 21 & 100 \\
\hline 7 & 857 & $(A C)_{8} Y G$ & 51 & $\begin{array}{l}220- \\
1750\end{array}$ & 20 & 19 & 95 \\
\hline 8 & 868 & $(\mathrm{GAA})_{6}$ & 52 & $\begin{array}{l}290- \\
1550\end{array}$ & 11 & 10 & 90.61 \\
\hline 9 & 834 & $(\mathrm{AG})_{8} \mathrm{YT}$ & 52 & $\begin{array}{l}250- \\
1300\end{array}$ & 9 & 9 & 100 \\
\hline 10 & 841 & $(\mathrm{GA}){ }_{8} \mathrm{YC}$ & 52 & $\begin{array}{l}200- \\
1270\end{array}$ & 13 & 12 & 92.31 \\
\hline 11 & 850 & $(\mathrm{GT}){ }_{8} \mathrm{YC}$ & 51 & $\begin{array}{l}200- \\
1250\end{array}$ & 6 & 6 & 100 \\
\hline 12 & 866 & $\begin{array}{l}\text { (CTC) } \\
{ }_{6} \mathrm{GT}\end{array}$ & 52 & $\begin{array}{l}300- \\
2000\end{array}$ & 14 & 14 & 100 \\
\hline 13 & 880 & $\begin{array}{l}(\text { GGAGA) } \\
3\end{array}$ & 51 & $\begin{array}{l}300- \\
1750\end{array}$ & 7 & 5 & 71.43 \\
\hline 14 & 881 & $\begin{array}{l}\text { (GGGGT) } \\
{ }_{3} G\end{array}$ & 57 & $\begin{array}{l}400- \\
1250\end{array}$ & 6 & 6 & 100 \\
\hline 15 & 860 & $(\mathrm{TG})_{8} \mathrm{RA}$ & 53 & $\begin{array}{l}270- \\
1800\end{array}$ & 8 & 6 & 75 \\
\hline 16 & 816 & $(\mathrm{CA})_{8} \mathrm{~T}$ & 47 & $\begin{array}{l}300- \\
1500\end{array}$ & 7 & 4 & 57.14 \\
\hline 17 & 873 & $(\mathrm{GACA})_{4}$ & 52 & $400-900$ & 7 & 7 & 100 \\
\hline
\end{tabular}




\begin{tabular}{|llllllll|}
\hline $\begin{array}{l}\text { SI } \\
\text { No }\end{array}$ & $\begin{array}{l}\text { Primer } \\
(\mathrm{UBC})\end{array}$ & $\begin{array}{l}\text { Primer } \\
\text { Sequence }\end{array}$ & $\begin{array}{l}\text { Annealing } \\
\text { Temperature } \\
\left({ }^{\circ} \mathrm{C}\right)\end{array}$ & $\begin{array}{l}\text { Fragment } \\
\text { size } \\
\text { range } \\
(\mathbf{b p})\end{array}$ & $\begin{array}{l}\text { Number } \\
\text { of } \\
\text { fragments }\end{array}$ & $\begin{array}{l}\text { Number of } \\
\text { polymorphic } \\
\text { loci }\end{array}$ & $\begin{array}{l}\text { Polymorphism } \\
(\%)\end{array}$ \\
\hline 18 & 840 & $(\mathrm{GA})_{8} \mathrm{TT}$ & 49 & $\begin{array}{l}250- \\
1220\end{array}$ & 10 & 5 & 71.43 \\
\hline
\end{tabular}

Several ISSR fragments showed fixed frequencies in individual accessions. Accession specific polymorphisms were obtained for 20 of the 50 small cardamom accessions tested (Table 3 ). The reproducibility of the amplification pattern was checked by repeating each reaction twice under the identical conditions. Of the 20 specific polymorphisms, 14 accessions were characterized by the presence of bands and the rest by the absence of bands. Unique bands were obtained for most of the released varieties under study. Primers UBC 857 and UBC 807 have given specific fragments for the released varieties. The accession MCC7 a vazhukka (semi-erect) type, exhibited the maximum number of unique bands (Table 3). 
Table 3

Accession - specific bands revealed by ISSR fingerprinting for analyzed small cardamom accessions

$\begin{array}{lll}\text { Cultivar } & \begin{array}{l}\text { Characterised by presence of ISSR } \\ \text { markers }\end{array} & \begin{array}{l}\text { Characterised by absence of ISSR } \\ \text { markers }\end{array}\end{array}$

ICRI 1 UBC860-500

ICRI $5 \quad$ UBC860-520

ICRI $4 \quad$ UBC807-1000

ICRI $7 \quad$ UBC807-1400

MCC $47 \quad$ UBC807-720

ICRI6

UBC812-900

ICRI $8 \quad$ UBC812-650

UBC866-450

MCC70 UBC841-800

Typical

UBC812-600

Mysore

$\begin{array}{ll}\text { MCC 38 } & \text { UBC828-550 } \\ \text { MCC 48 } & \text { UBC828-700 } \\ \text { MCC 65 } & \text { UBC857-900 } \\ \text { MCC6 } & \text { UBC857-690 }\end{array}$

MCC $7 \quad$ UBC828-420, UBC873-600,

UBC857-520, 600

UBC866-450

IISR Avinash UBC850-950, UBC866

IISR Vijetha UBC828-900

CRS Mudigere

UBC828-750 I

MCC4

UBC866-750

MCC 36

UBC873-300

MCC 53

UBC841-450 
The primer UBC866 produced a clear fragment (approximately 1500bp) unique to Malabar variety (prostrate panicle), but was absent in all DNA samples of Mysore and Vazhukka varieties (Fig. 2). This fragment produced by UBC-866 was selected as a putative variety-specific marker.

\section{Cloning of ISSR UBC $866_{1500}$ fragment}

The characteristic DNA fragment amplified by ISSR UBC 866 was eluted and ligated to pTZ57R vector by InsTAclone PCR cloning kit. Blue and white colonies were obtained and white colonies were cultured (Supplementary figure S1). The positive clones were then confirmed by PCR amplification using M13 universal primers (Supplementary figure S2). Blue colony (without insert) was used as a control for comparing the results. All clones from recombinant colonies showed fragments similar to the inserted fragment except the blue colony, which produced fragment of $\sim 750 \mathrm{bp}$ in size. The recombinant clones were selected for sequencing.

The sequence of the prostrate panicle-specific fragment of 1534 bp (Fig. 3) was deposited in GenBank (Accession number: MN276062). The sequence analysis of cloned product revealed that the $1534 \mathrm{bp}$ ISSR fragment was bordered by the original bases of the microsatellite repeats and no repeats were found within the sequence. BLAST searches of the nucleotide sequences with the NCBI nucleotide database using BlastN tool did not reveal any significant match with any known nucleotide sequence, which confirmed the first report of this SCAR marker.

To generate a stable Malabar-specific diagnostic SCAR marker, ten pairs of primers were designed and synthesized based on cloned sequences and were named SBBT 1-10 (Supplementary table-1). The efficacy of each SCAR primer set for amplification of specific PCR product size in particular variety was assessed using DNA from each of the three varieties. Of the 10 SCAR primers designed only a single primer pair SBBT4F and SBBT3R (Table 4) produced specific fragment in Malabar variety and this was used for further validation.

Table 4

Characteristics of SCAR developed for distinguishing Malabar variety

\begin{tabular}{|lllllll|}
\hline $\begin{array}{l}\text { ISSR } \\
\text { primer }\end{array}$ & $\begin{array}{l}\text { Variety } \\
\text { specific } \\
\text { locus }\end{array}$ & $\begin{array}{l}\text { Cloned } \\
\text { sequence } \\
\text { length (bp) }\end{array}$ & $\begin{array}{l}\text { SCAR } \\
\text { primer } \\
\text { pair }\end{array}$ & Primer sequence & $\begin{array}{l}\text { Tm } \\
\text { ('C) }\end{array}$ & $\begin{array}{l}\text { Amplicon } \\
\text { length } \\
\text { (bp) }\end{array}$ \\
\hline \begin{tabular}{lllllll|} 
UBC \\
866
\end{tabular} & $\begin{array}{l}\text { UBC 866- } \\
1500\end{array}$ & 1534 & SBBT4F & GGAGGTCGGCTATGATCTGC & 57 & 1350 \\
\cline { 3 - 4 } & & SBBT3R & CATCTGGATGAAAGCCCACT & & \\
\hline
\end{tabular}

\section{Validation of the designed SCAR marker}

The SCAR marker primer pair (SBBT4F and SBBT3R) was used to amplify 24 samples to test varietyspecificity at an annealing temperature of $57^{\circ} \mathrm{C}$ (Fig. 4). The 24 tested accessions include 21 Malabar 
accessions (prostrate panicles), 2 erect panicles and 1 semi-erect panicle types. A clear specific band was detected in $95 \%$ of prostrate panicle type but not in samples of erect and semi-erect accessions (Fig. 4). The result revealed that the SCAR primer SBBT $4 \mathrm{~F}$ and SBBT $3 \mathrm{R}$ that produced specific fragment $(\sim 1350$ bp) in prostrate panicle is indicative of its Malabar-specificity. Moreover, the initial UBC866 primer was also analysed in the same gel in Malabar and Mysore accession to confirm the product size and specificity. This validated the relevance of designing Malabar- variety specific SCAR marker.

\section{Discussion}

The present study was to identify suitable ISSR polymorphisms among cardamom varieties and to transform them into more-specific SCAR markers in an efficient and reliable manner. ISSR reported first by Zietkiewicz (1994) is a popular marker system, owing to their reproducibility, ability to detect polymorphisms, and cost-effectiveness. The reliability of the ISSR marker system has been supported by different investigators in a wide range of crop species including wheat (Nagaoka \& Ogihara 1997) and rice (Joshi et al. 2000). In the present study, a specific ISSR fragment of high intensity and reproducibility was identified for Malabar varieties (prostrate panicle) and was used for development of SCAR primers for consistent and repeatable amplification. Subsequently a Malabar variety-specific SCAR marker was developed from the sequence derived from ISSR primer UBC-866. The developed SCAR marker (SBBT4F/SBBT3R) was specific to DNA from all Malabar varieties, as they showed no amplification of DNA from Mysore and Vazhukka varieties. Nucleotide BLAST analyses of ISSR sequence did not reveal any homology to documented GenBank sequences, thereby proving that sequence of the marker under discussion does not belong to any identified portion of the small cardamom genome.

The development and characterization of SCAR markers is a valuable molecular technique for the genetic identification of any species. This method is mainly derived from the molecular cloning of the amplified DNA fragments achieved from the dominant markers. Since, SCAR markers are more straightforward than RAPD, ISSR and AFLP, they can identify a single or few bands instead of a complex pattern (Fu et al. 2015). So identification of any organism becomes more authentic and well-verified if molecular marker analysis is combined to SCAR marker technology (Surendra et al. 2012). Recently, SCAR markers have been used widely for discriminating plant species/varieties for different conditions and traits. Surendra et al. (2012) used SCAR marker for varietal identification in fenugreek, whereas and Rajesh et al (2013) developed RAPD-SCAR marker for identifying tall-type palm trait in coconut. Semsang et al. (2013) utilized SCAR markers for identifying Thai fragrant rice mutants. Singh et al. (2017) used SCAR marker for differentiating Gladiolus germplasm and Hao et al. (2018) used SCOT (Start Codon Targeted polymorphism) based SCAR for authentication of Taxus media. Boyd et al. (2019) distinguished red maple from silver maple using species-specific SCAR markers.

Madhusoodanan et al. (1994) reported that phenotypic variants exist naturally due to the cross-pollinating nature of cardamom. Among this morphological variability, the panicle type such as prostrate, erect and semi-erect panicles were considered as the major discriminative morphological varietal markers of cardamom. In the present study, $95 \%$ of the prostrate panicle type (Malabar group) expressed the variety- 
specific band however it was absent in erect and semi-erect types. This might be due to the presence of distinct variability within and between the cardamom varieties as reported by Padmini et al (1999) based on assessment of morphological characteristics. Varietal identification is important for breeding processes and to protect breeder's rights for newly developed varieties. Presently, the traditional methods for characterization and assessment of genetic variability in many plant species including cardamom, based on morphological, physiological and biochemical studies, per se are time consuming and affected by the environment.

Designing SCAR markers for varietal identification would be of immense use for crops like cardamom, where accurate identification of taxonomic status persists as a long-term problem. Due to many remarkable characteristics of Malabar variety, the present results with SCAR markers would be very useful for identifying Malabar varieties and thereby reducing the time and labour during breeding programmes. This is the first study on ISSR-SCAR in Elettaria for varietal identification.

\section{Conclusion}

The variety-specific SCAR marker developed during the course of the present investigation proved to be reliable and efficient for discriminating small cardamom varieties based on panicle morphology. The specific primer pair (SBBT4F/SBBT3R) clearly demonstrated this unique band only in Malabar varieties and not in Mysore and Vazhukka varieties of cardamom. The SCAR marker reported here could be used for effective and rapid identification of this variety, for utilizing in plant breeding activities.

\section{Declarations}

\section{Acknowledgement}

The authors are thankful to Department of Biotechnology, Government of India and Spices Board, Govt. of India for providing financial assistance.

\section{Funding}

The research was funded by Department of Biotechnology, Government of India and Spices Board, Govt. of India.

\section{Conflict of Interest}

The authors declare that they have no conflict of interest to disclose.

\section{Availability of data and material}

All data are included in the manuscript.

\section{Code availability}


Not applicable

\section{Authors' contributions}

SJ conceived, designed and executed the experiments, collected the plant material and analyzed the experimental data. SS and ACS provided experimental help in the laboratory. MMK and RYS conceived the overall research project and are the PI's for the initiative. SJ wrote the manuscript and MMK provided editorial advice. All authors revised and approved the final version of the manuscript.

\section{Ethics approval}

This article does not contain any studies with human participants or animals performed by any of the authors.

\section{Consent to Participate}

Not applicable

\section{Consent for Publication}

All authors consented for publication in this journal

\section{References}

1. Abraham P, Tulasidas G (1958) South Indian cardamoms and their agricultural value. ICAR Bulletin 79:1-27.

2. Anonymous (1976) Annual Report Central Plantation Crops Research Institute Kasaragod, India.

3. Boyd M, Panoyan MA, Michael P, Nkongolo KK (2019) Development and characterization of speciesdiagnostic ISSR and SCAR DNA markers for differentiating red maple (Acer rubrum) and silver maple (A. saccharinum). Genome. 62. 10.1139/gen-2019-0037.

4. Das M, Bhattacharya S, Pal A (2005) Generation and characterization of SCARs by cloning and sequencing of RAPD products: A strategy for species-specific marker development in bamboo. Annals of Botany 95(5): 835-841.

5. Das M, Bhattacharya S, Singh P, Filgueiras TS, Pal A (2008) Bamboo Taxonomy and Diversity in the Era of Molecular Markers. Advances in Botanical Research 47:225-260

6. Fu JJ, Mei ZQ, Tania M, Yang LQ, Cheng JL, Khan MA (2015) Development of RAPD-SCAR markers for different ganoderma species authentication by improved RAPD amplification and molecular cloning. Genetics and Molecular Research 14(2):5667-5676. doi:10.4238/2015

7. Govindarajan VS, Shanti N, Raghuveer KG, Lewis YS (1982) Cardamom- Production, technology chemistry and quality. CRC Critical Rev. Food Sci. Nutrition 16: 326

8. Ghosh M, Chezhian P, Sumathi R, Yasodha R (2011) Development of SCAR marker in Casuarina equisetifolia for species authentication. Trees 25(3):465-472 https://doi.org/10.1007/s00468-010- 
0522-x.

9. Hao J, Jiao K, Yu C, Guo H, Zhu Y, Yang X, et al (2018) Development of SCoT-based SCAR marker for rapid authentication of taxus media. Biochemical Genetics 56(3):255-266 https://doi.org/10.1007/s10528-018-9842-0.

10. IPGRI (1994) Descriptors for cardamom (Elettaria cardamomum Maton). International Plant Genetic Resources Institute. Rome, pp. $27-41$.

11. Joshi SP, Gupta VS, Aggarwal RK, Ranjekar PK, Brar DS (2000) Genetic diversity and phylogenetic relationship as revealed by inter simple sequence repeat (ISSR) polymorphism in the genus Oryza. Theoretical and Applied Genetics 100: 1311-1320 https://doi.org/10.1007/s001220051440.

12. Korikanthimath VS (2003) Cardamom (Small). Handbook of Herbs and Spices. In: Peter KV (ed) Vol 1 CRC Press, Wood Head Publishing Ltd, Cambridge, England, U K, pp 123- 133.

13. Madhusoodanan KJ, Kuruvilla KM, Priyadarshan PM (1994) Genetic resources of cardamom. In: Chadha KL, Rethinam P (eds) Advances in Horticulture, vol 9, plantation and spice crops, part I. Malhotra Publishing House, New Delhi, pp 121-130

14. Madhusoodanan K, Kumar KP, Ravindran P (2002) Botany, crop improvement and biotechnology of cardamom. Cardamom (pp. 27-84) CRC Press.

15. Mathew MK, Jose S, Rao Y, Gupta U, Thomas J (2014) Optimization of genomic DNA extraction from fresh and dry leaves of large cardamom (Amomum subulatum Roxb.) for diversity analysis. Indian Journal of Biotechnology 13:221-224. http://nopr.niscair.res.in/handle/123456789/29144.

16. Mayne WW (1951) Report on cardamom cultivation in South India. Indian Council of Agricultural Research Bulletin 50:1-80.

17. Nagaoka T, Ogihara Y (1997) Applicability of inter-simple sequence repeat polymorphisms in wheat for use as DNA markers in comparison to RFLP and RAPD markers. Theor. Appl. Genet 94:597-602.

18. Nirmal Babu K, Jayakumar V, MINOO D, Venugopal M, Sudarshan M, Radhakrishnan V, et al (2012) Genetic diversity and phylogenetic relationships among small cardamom (Elettaria cardamomum Maton.) cultivars and related genera using DNA markers. International Journal of Innovative Horticulture 1:47-56.

19. Nkongolo KK, Deverno L, Michael P (2003) Genetic validation and characterization of RAPD markers differentiating black and red spruces: molecular certification of spruce trees and hybrids. Plant Syst Evol 236:151-163. doi: 10.1007/s00606-002-0236-7.

20. Padmini K, Venugopal MN, Korikanthimath VS (1999) Biodiversity and conservation of cardamom (Elettaria cardamomum Maton). In Sasikumar B, Krishnamoorthy B, Rema J, Ravindran PN, Peter KV (eds) Biodiversity, Conservation and Utilization of Spices, Medicinal and Aromatic Plants, IISR, Calicut, pp.73-78.

21. Rajesh M, Jerard B, Preethi P, Thomas RJ, Fayas T, Rachana K, et al (2013) Development of a RAPDderived SCAR marker associated with tall-type palm trait in coconut. Scientia Horticulturae, 150:312316. https://doi.org/10.1016/j.scienta.2012.11.023. 
22. Semsang N, Chundet R, Phanchisri B (2013) Development of a SCAR marker for discrimination of a Thai jasmine rice (Oryza sativa L. cv. KDML105) mutant, BKOS6, and associated with purple colour trait in Thai jasmine rice-related varieties. Am J Plant Sci 4:1774-1783.

doi: 10.4236/ajps.2013.49218.

23. Singh N, Pal AK, Meena B, Roy RK, Tamta S, Rana TS (2017) Development of ISSR- and RAPD-derived SCAR markers for identification of Gladiolus germplasm. Journal of Horticultural Science and Biotechnology 92:677-682. doi:10.1080/14620316.2017.1309995.

24. Surendra KC, Kumar V, Srivastava N, Singh A, Vyas MK, Gupta S, Katudia K, Vaidya K, Chaudhary S, Ghosh A (2012) Genetic diversity and identification of variety-specific AFLP markers in fenugreek (Trigonella foenum-graecum). African Journal of Biotechnology 11(19): 4323-4329. 10.5897/AJB11.3095.

25. Zietkiewicz E, Rafalski A, Labuda D (1994) Genome fingerprinting by simple sequence repeat (SSR)anchored polymerase chain reaction amplification. Genomics 20:176-183. https://doi.org/10.1006/geno.1994.1151.

\section{Figures}

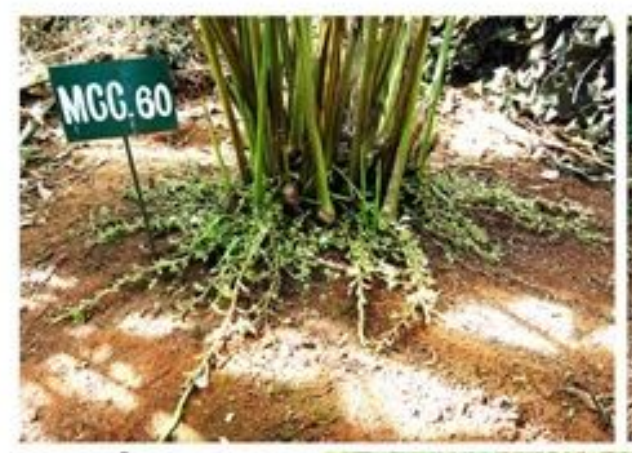

A

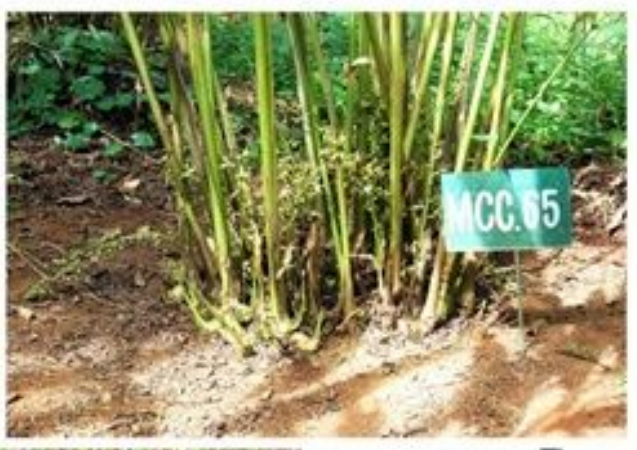

B

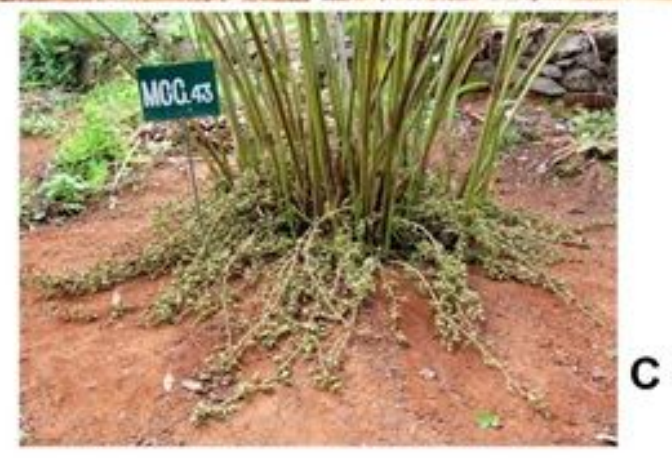

\section{Figure 1}

Botanical varieties of cardamom. A) Malabar; B) Mysore and C) Vazhukka 


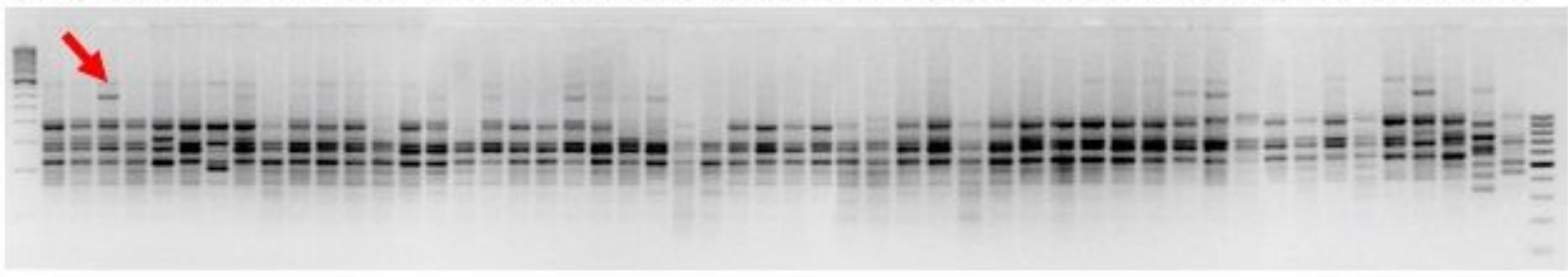

M- 250bpladder; 1-ICRI1, 2-ICRI2, 3-ICRI3, 4-ICRI5, 5-MCC4, 6-MCC6, 7-MCC7, 8-MCC8, 9-MCC12, 10 MCC34, 11-PV1, 12-MCC36,13- MCC37, 14-MCC38, 15- MCC39, 16-MCC40, 17-MCC41, 18-MCC42, $19-$ MCC43, 20-MCC44, 21-MCC45, 22-MCC46, 23-MCC47, 24-MCC48, 25-MCC50, 26-MCC51, 27-MCC52, 28MCC53, 29-MCC55, 30-MCC58, 31-MCC60, 32-MCC64, 33-MCC65, 34-MCC66, 35-MCC67, 36-MCC69, 37. MCC70, 38-MCC71, 39-MCC72, 40-MCC260, 41-CRS Mudigere1, 42-IISR Vijetha, 43-IISR Avinash, 44-MCC5, 45-ICRI7, 46-ICRI4, 47-ICRI6, 48-Typical Mysore, 49-ICRI8, 50-MCC334, 51-A.muricatum, 52-A.subulatum; M$100 \mathrm{bp}$ ladder

\section{Figure 2}

Variety specific bands produced by ISSR marker UBC 866

GCCGACTAGACTCGCGATGCATCTAGATTCTCCTCCTCCTCCTCCTCGTATTCGCTTCCGGATTCATTCGGTTGCCCC TTCGTGACCGGCGACGGACACCGCTCCTTCAGGCGTCGGCCAGCCCACTGCACCATTTCCCACGCACCACCCAATT TTTATTCCCAATTCAAGCACTTACTGGAACTCTGCCTGCCATGCAACTCTGTGACCGCACCACGTCCTCCACCTCCAC CCACGTATTCTCCTCCCAGTTGCCATCTGGATGAAAGCCGCACGACTATAATTATAGCTACTACCACCGTCTTACAT ATGCCATCGGATCATCGCTCTCCAAATTAACCTCTATTCTTGGCATCCTTGCTTTGGTACGTAGGAGAATCATCTACC TTTAATTTCGTTTTCCTAGCGAGTAGAACCATAACTAATTGTTGAACTTGTGCTTTACGTGCATGCGTGAGCTTAGA TTACTGGTGAATGGCATCGCGGGAAGCAATAAGCAAAGTGAGAATAGGGAAGACGACGACGTACCGGAAGGGC ACCGATACGGAACTGCTTGCCTTCGGAAGCGAAGCGGCGATGGCAGCCAAGCTGCTGGTTTTGGGAGGCGACGG CGGCGGCAGGCAGGTCTTCCGCGCTGGACGGCTTTCCGTACACATGATCCGGGTGGCGTCCTCCCCCCGTGTGCTT GGTCAGTTGCATGGTCGGGGATCACCTCTGGACGATGGCAAGGGACGCGGTCGTCCTCCGGGCAGCTCCGCGCA GGTACGCCTTCGCTATGCCGGGATTCTGCTACGGCCTTTCGCTGCCCTGCTCCGGTGGCGCCTACGAGCACAAGTG CCGAACGCTGGAGGAGATGCTCCTCCGGTTTTGCGCCTTCCGGCGCCTCGAAGGTGCGATCAATTTTAATCTTCAA CCCTTTCCGATTTGCGCGCGCCGAGATCAATTTTTTGCTTTGATTTCTTGCGCGCCAAGATCAATTTATTATTTGATT CTTGGTGGTTAGAATACTTTCCGCGTGACAAGATCAAGTTCTTATCTTCATTCAGGTTATTCTTTCTCGTGGCGAAA GTGAATCAGGCGACGTTGGGCGGTATGCTTACGAGGAGATCGAGATAGTTCACCTTATGTGACTGTACACGTTCG TATCTCTTAGTTTTGTGTTTTTTGTTTGTTCCTTGTTATGGGTTGAACTAGCGGGCGGTGAGGACGTCGGCGGTGGT GAAGCTGCTCTCTCGTTCCCTCCTCACTGGCGCTCTCGACCCTCGGAAGCACCTCGATCTGACCGCCGGCACCTCCC TCCCCAGCATGCAGATCATAGCCGACCTCCTGGACGTGATCGAGACGGGGAGGCGACGGGATCCGATGTCGCCG GCGGCGGCGACGCCCAGTGGGCTCTGGTGCATCAACrGCAGAGGGGTTGAAGCTGCTGGTGTTGGTACTTTCGGC GTGCAGCACCGCGGCGAAGAGAAAAAGGCAGCCGCTAGAGACGCTGAACGAGGAGGAGGAGGAGGAGAA

\section{Figure 3}

Nucleotide sequence of ISSR UBC- 866 specific to the Malabar variety (prostrate panicle) flanked by the SSR sequences (underlined) 

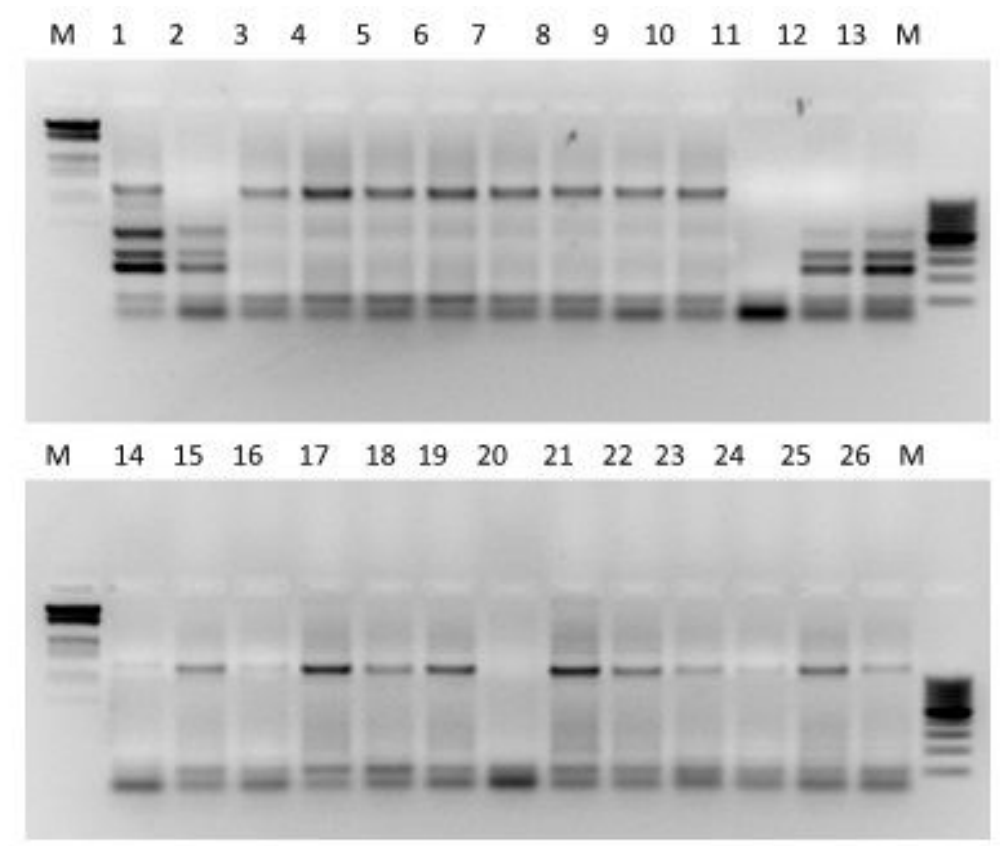

\section{Figure 4}

Amplification profile of SCAR marker SBBT4F/SBBT3R in small cardamom accessions. Lane M- 250bp ladder; lane (1\&2) Malabar and Mysore variety resp using ISSR UBC 866 primer; lane (3-10) Malabar accessions (prostrate panicle); lane (11) Vazhukka (semi-erect panicle); lane (12\&13) Mysore (erect panicle); and lane (14-26) Malabar accessions (prostrate panicle) last lane (M) 100bp ladder.

\section{Supplementary Files}

This is a list of supplementary files associated with this preprint. Click to download.

- SupplementaryFile.pdf 